\title{
Neurophysiological and Neuroradiological Changes in children with chronic kidney disease
}

\section{Sameh Abd El Naby}

Menoufia University Faculty of Medicine

\section{Ali El-Shafie}

Menoufia University Faculty of Medicine

Wael Bahbah

Menoufia University Faculty of Medicine

Asmaa Mahmoud ( $\square$ asmaasoliman50@gmail.com )

Menoufia University Faculty of Medicine https://orcid.org/0000-0002-2366-8009

\section{Research article}

Keywords: chronic kidney disease, nerve conduction, EEG, EMG, MRI.

Posted Date: April 9th, 2020

DOl: https://doi.org/10.21203/rs.3.rs-21054/v1

License: (9) This work is licensed under a Creative Commons Attribution 4.0 International License. Read Full License

Version of Record: A version of this preprint was published on November 16th, 2020. See the published version at https://doi.org/10.3389/fped.2020.570708. 


\section{Abstract}

Background: Patients with chronic kidney disease on hemodialysis are frequently afflicted with neurological complications. These complications can potentially affect both the central and peripheral nervous systems. Common neurological complications in CKD include stroke, cognitive dysfunction, and encephalopathy, peripheral and autonomic neuropathies.

Aim: to detect the neurological manifestations and complications in children with chronic kidney disease through neurophysiological and neuro-radiological findings.

Methods: The study included 50 patients with CKD admitted to pediatric nephrology unit. Their history, complete physical and neurological examination finding had been recorded. All of them underwent nerve conduction, electromyography (EMG), electroencephalography (EEG) and magnetic resonance imaging (MRI).

Results: Included children were 23 males and 27 females with mean age of ( $12.8 \pm 3.44$ year). 11 (22\%) patients of end stage renal disease developed polyneuropathy mostly of axonal polyneuropathy pattern while $78 \%$ of them showed normal electrophysiological studies. No myopathy was detected. Abnormal electroencephalography findings were detected in $18 \%$ of patients in the form of generalized and focal (temporal, occipital and frontal) epileptogenic activity had been found. Abnormal MRI findings were detected in $16 \%$ of patients mostly of encephalomalachia.

Conclusion: Neurological status in patients with end stage renal disease on maintenance hemodialysis therapy was impaired. Uremic neuropathy is highly prevalent in these patients. They developed polyneuropathy mostly of axonal polyneuropathy pattern. EEG is a useful tool for detection of subclinical or latent uremic encephalopathy and/or epileptogenic activity. Early detection and management of these neurological conditions may estimate a window to reduce physical disability in children with CKD.

\section{Introduction}

Chronic kidney disease (CKD) is defined by the National Kidney Foundation Kidney Disease and Outcome Quality Initiative (KDOQI) Group as CKD is present if the glomerular filtration rate (GFR) is less than $60 \mathrm{~mL} / \mathrm{min}$ per $1.73 \mathrm{~m}^{2}$ for $\geq 3$ months or if the GFR is $\geq 60 \mathrm{~mL} / \mathrm{min}$ per $1.73 \mathrm{~m}^{2}$ if other evidence of kidney damage exists which is manifested by pathologic abnormalities reported by renal biopsy or abnormalities detected by urine, blood tests and imaging procedures ${ }^{(1)}$.

The etiology of CKD may be due to a primary renal disorder or as a multisystem disorder complication related to comorbidities, such as diabetes which is considered now the leading cause of CKD worldwide. Neurological complications are highly prevalent in CKD whatever the cause (2).

Encephalopathy that detected in patients with chronic kidney disease may be due to their exposure to several factors as uremia, hypertension, and fluid and electrolyte disturbances ${ }^{(3)}$. Uremic encephalopathy 
features including alterations of the mental status (alertness and awareness alterations, poor concentration, psychosis, hallucinations, without treatment stupor and coma may develop) and motor system abnormalities as clouding of sensorium as early feature and delirium, seizures, coma as late features ${ }^{(4)}$.

Dialysis disequilibrium syndrome neurological manifestations include headache, nausea, vomiting, blurred vision, muscle cramps, tremor, disturbed consciousness and convulsions due to rapid removal of urea during hemodialysis. Rapid hemodialysis leads to osmotic gradient between plasma and brain resulting in cerebral edema that manifest neurological status for these patients ${ }^{(5)}$.

The most common neurological complication of CKD is peripheral neuropathy that also called uremic neuropathy that affects $60-90 \%$ of dialysis patients ${ }^{(6)}$. Early clinical features of uremic neuropathy are numbness and paresthesia resulting from involvement of large myelinated sensory fibers and clinical examination reveals distal sensory loss in lower limb and decreased or absent deep tendon reflexes. With motor involvement, weakness and muscle atrophy developed with more severe conditions ${ }^{(7)}$. When GFR level decreased below $12 \mathrm{ml} / \mathrm{min}$, clinical manifestations of uremic neuropathy becomes clear ${ }^{(8)}$.

Uremic myopathy mechanism in CKD is unclear but may occur due to the role of oxidative stress (9). When glomerular filtration rate decreases below $25 \mathrm{~mL} / \mathrm{min}$ with impairment of kidney function, uremic myopathy clinical features will appear ${ }^{(10)}$ as proximal muscle weakness in the muscles of the lower limbs leading to limited function of these muscles ${ }^{(11)}$.

Stroke display a high prevalence in patients with CKD. The prevalence is $17 \%$ for long term hemodialysis CKD patients, $10 \%$ for mild to moderate CKD patients and $4 \%$ for the general population. $50 \%$ of advanced CKD patients have evidence of silent brain infarcts on magnetic resonance imaging (MRI) ${ }^{(12)}$. Hypertension, hypercholesterolemia, disorders of mineral and bone metabolism increase the risk of stroke (13).

The aim of this work was to detect the neurological manifestations and complications in children with chronic kidney disease through neurophysiological and neuro-radiological findings.

\section{Subjects And Methods}

This cross sectional study was carried out on 50 children presented by chronic kidney disease. Patients were selected from the Nephrology unit, Pediatric department, Menoufia University Hospital. Children included in this study were less than 18 years and on regular hemodialysis for more than 6 months. They were 23 males and 27 females with mean age of (12.8 \pm 3.44 year). Patients having central or peripheral nervous system disease from congenital or other causes than CKD, and who have previous polyneuropathy and myopathy caused by thyroid dysfunction or diabetes mellitus were excludes from the study. 
The study was approved by the faculty ethical committee after taking written consent from patients' guardians after a full explanation of benefits and risks of the study.

\section{Methods}

All studied patients were subjected to complete history taking, complete physical and neurological clinical examination. Polyneuropathy was assessed clinically (numbness, tingling, insomnia, pain or paresthesia), by examination (distal motor wasting, weakness, hypotonia and hyporeflexia), and electrophysiologically by nerve conduction and electromyography (EMG) that confirm the diagnosis and detecting type of polyneuropathy (axonal or demyelinating). Myopathy was assessed clinically through proximal weakness and wasting and electrophysiological by nerve conduction and (EMG) studies that confirm the diagnosis and determining the muscle affected. All studied patients underwent nerve conduction, electromyography (EMG), electroencephalography (EEG) and magnetic resonance imaging.

\section{Neurophysiological Studies:}

\section{A) Nerve Conduction And Electromyography (emg):}

All patients in the current study were assessed by neurophysiology studies in the form of a nerve conduction including motor and sensory evaluation as well as electromyography (EMG). The examined nerves included tibial and peroneal nerves on both sides (motor) and sural nerve on both sides (sensory) while the examined muscles included the tibialis anterior, medial head of gastrocnemius medial and gluteus maximus muscles on both sides.

\section{Diagnostic Criteria Of Polyneuropathy And Myopathy:}

Diagnosis of myopathy was assessed based on normal nerve conduction study, needle EMG reports short duration, and low amplitude motor potential with early or normal full recruitment in proximal muscles (gluteus maximus) (14).

Axonal polyneuropathy diagnosis detected on the basis of the nerve conduction study that illustrates decreased compound muscle action potential (CMAP) amplitudes to $<80 \%$ of the lower bound of normal in two or more nerves without conduction block, decreased sensory nerve action potential (SNAP) amplitudes to $<80 \%$ of the lower bound of normal and normal or near normal nerve conduction velocities without conduction block.

On the basis of diagnosis of axonal polyneuropathy by EMG study that illustrates denervation potential (fibrillation, positive sharp waves) in distal muscle, large polyphasic motor unit and reduced recruitment of motor potential in distal muscle. 
Acute demyelination polyneuropathy was diagnosed based on nerve conduction study which demonstrates prolonged distal motor latency $>115 \%$ of the upper limit of normal, decreased conduction velocity $<90 \%$ of the lower limit of normal and conduction block ${ }^{(15)}$.

On the basis of diagnosis of acute demyelination polyneuropathy by EMG study which demonstrates no denervation potential at rest in distal muscle, normal motor unit and reduced recruitment of motor potential in distal muscles.

\section{B) Electroencephalogram (eeg):}

The EEG was performed in a quiet room using Galileo Sirius9231134. The 21-channel-EEGs were recorded during standard conditions (rest, hyperventilation, photo stimulation); children were studied while resting with eyes closed throughout the recording period. EEG signals were recorded for 20 min from 19 scalp electrodes, according to the International 10-20 System using an average reference (Mizar-Sirius 33 Channels; EBNeuro) ${ }^{(16)}$.

\section{Statistical analysis}

The collected data were tabulated and analyzed by SPSS (statistical package for social science) version 22.0 on IBM compatible computer. Two types of statistics were done: Descriptive statistics in which percentage (\%), mean and standard deviation (SD) were used while for analytical statistics: Student t-test: used for comparison between two groups having quantitative parametric variables. A p-value $\leq 0.05$ was considered significant.

\section{Results}

Demographic features and clinical profile were illustrated in (Table 1). Seizures were reported in $22 \%(\mathrm{n}=$ 11), headache in $24 \%(n=12)$, numbness in $18 \%(n=9)$, dizziness in $10 \%(n=5)$, insomnia in $14 \%(n=7)$, memory disturbance in $6 \%(n=3)$, delayed speech in $8 \%(n=4)$, hypotonia in $22 \%(n=11)$, hyporeflexia in $22 \%(n=11)$ and hyperreflexia in $10 \%(n=5)$ of children with CKD.

The prevalence of peripheral neuropathy among studied patients detected through electrophysiological study was $22 \%$ ( $n=11$ of 50 ), axonal motor and sensory neuropathy was observed in $81.8 \%(n=9)$, demyelinating motor neuropathy was reported in $18.2 \%(n=2)$ as shown in (Table 2$)$. By the analysis of nerve conduction study, the results revealed a highly significant statistical difference between the two groups regarding amplitude, which was markedly reduced in the patient group, and in conduction velocity which was markedly reduced in the patient group in comparison to the control group of tibial and peroneal nerves. Also, there was a highly significant statistical difference between both groups concerning the distal motor latencies (Table 3).

By the analysis of EMG study, the results revealed normal motor units in 41 patients (82\%) while 9 patients (18\%) revealed large polyphasic motor unit (neuropathic) as regards tibialis anterior muscle and 
medial head of gastrocnemius muscle while all studied patients $(100 \%)$ revealed normal motor unit as regards gluteus maximus muscle. There was a decreased interference pattern in 11 patients $(22 \%)$ and denervation potential in the tibialis anterior and medial head of the gastrocnemius muscles in 9 patients (18\%) (Table 4).

Abnormal EEG findings were demonstrated in $18 \%(n=9)$ of studied subjects, $44.4 \%(n=4)$ had generalized epileptogenic activity, and $55.6 \%(n=5)$ had focal epileptogenic activity (40\% temporal, $40 \%$ occipital and $20 \%$ frontal) as illustrated in (Table 5). Abnormal MRI findings were reported in 8 patients $(16 \%)$ including mild brain atrophy in $37.5 \%(n=3)$ and encephalomalacia in $62.5 \%(n=5)$ as shown in (Table 6).

\section{Discussion}

Sensorimotor axonal polyneuropathy are common and affects lower limbs mainly due to length dependent axonal degradation and secondary focal loss of myelin sheath $(17,18)$.

The accumulation of uremic toxins associated to oxidative stress-related free radical activity causes motor, sensory and autonomic nerve damage which leads to uremic neuropathy $\left({ }^{19,20)}\right.$. Hyperkalemia and hyperphosphatemia cause chronic uremic depolarization of nerves that contributes to the development of UN. Potassium disrupts the normal ionic gradient and activates calcium-mediated processes leading to axonal death (21).

Seizures were reported in 11 (22\%) due to epilepsy and uncontrolled hypertension and headache in 12 (24\%) due to uncontrolled hypertension, both were the major central neurological manifestation in patients with CKD. This is in concordance with Afsharkhas et al. who reported that $12(40 \%)$ of patients had neurologic findings including seizures in $7(23.4 \%)$ patients due to epileptic syndromes, hypertension with posterior reversible encephalopathy syndrome, febrile convulsion, and increased intracranial tension ${ }^{(22)}$. Also, Scorza et al. reported 5 cases had seizures related to dialysis (23).

Analytical interpretation of the results of current neurophysiological study revealed neurological presentation of uremic neuropathy that vary from numbness, insomnia, weakness, hypotonia, and hyporeflexia. Early symptoms of UN are paresthesia, paradoxical heat sensation, restless leg syndrome, increased pain sensation, and cramps. Long-term symptoms include weakness, impaired deep tendon reflexes, imbalance, numbness, and atrophy of the lower limbs $(24,25)$.

Peripheral neuropathy prevalence in the current work was $22 \%$; axonal motor and sensory neuropathy $(81.8 \%)$ is more common than demyelinating motor neuropathy (18.2\%). Yoganathan et al. demonstrated that the prevalence of peripheral neuropathy was $52 \%$; axonal neuropathy $(80.8 \%)$ was more common than demyelinating neuropathy $(11.5 \%)$ and motor neuropathy was the predominant type, followed by sensory motor neuropathy ${ }^{(26)}$. Few studies in children reported that the prevalence ranging from $0-59 \%$ (27). In contrast, Ackil et al. showed that sural nerve conduction abnormalities in $59 \%$ of children, and 
motor conduction studies revealed motor conduction abnormality in $29 \%$ of children on dialysis ${ }^{(19)}$. The tibial and common peroneal nerves were most commonly affected as there was reduced conduction velocity and amplitude in our patients, this in agreement with Yoganathan et al. (26). Another study reported that low peroneal nerve conduction velocity was considered as a sensitive measure for the diagnosis of uremic neuropathy ${ }^{(28)}$. De Camargo et al. demonstrated significant decrease in mean peroneal motor nerve conduction velocity in children with mild renal failure ${ }^{(29)}$.

Analytical interpretation of EMG results of the current study revealed normal motor units in 41 patients (82\%) while 9 patients (18\%) revealed large polyphasic motor unit (neuropathic) as regards tibialis anterior muscle and medial head of gastrocnemius muscle and all studied patients (100\%) revealed normal motor unit as regards gluteus maximus muscle. There was a decreased interference pattern in 11 patients (22\%) and denervation potential in the tibialis anterior and medial head of the gastrocnemius muscles in 9 patients (18\%). Fahal and Bell reported normal electromyography (EMG) findings in patients with chronic kidney disease ${ }^{(11)}$. Berretta et al. revealed proximal muscle weakness primarily of the lower extremities and especially of the proximal musculature of the pelvic girdle and the electromyogram (EMG) illustrated high-voltage polyphasic potentials in a 13-year old boy with poor kidney function with elevated BUN( blood urea nitrogen) to $118 \mathrm{mg} / \mathrm{dl}$ and creatinine to $10.7 \mathrm{mg} / \mathrm{dl}{ }^{(30)}$.

Abnormal EEG findings were demonstrated in $18 \%(n=9)$ of studied subjects, $44.4 \%(n=4)$ had generalized epileptogenic activity, and $55.6 \%(n=5)$ had focal epileptogenic activity ( $40 \%$ temporal, $40 \%$ occipital and $20 \%$ frontal). Gadewar et al. ${ }^{(31)}$ showed that frontal and fronto-temporal sharp wave transients were reoresented as the stage of CKD was progressed and were present in stage 5 and stage 4, frontal sharp wave transients were reported in $50 \%$ of stage 5 and in $71.43 \%$ of stage 4 . Demir et al. (32) reported that bilateral spike wave activity was found in $14 \%$ of patients with uremic encephalopathy who don't have seizures. Also, Koçer et al. ${ }^{(33)}$ demonstrated that sharp wave transients in the later stages of CKD, and occipital sharp wave transients were found in stage 4 and p-value is reported to be significant in the distributional pattern at different progressive stages of CKD.

Electroencephalography (EEG) has generalized slowing, and bilateral spike and wave complexes have been described in up to $14 \%$ of patients, even in the absence of evident clinical seizure activity ${ }^{(34)}$. Arnold et al. reported the EEG abnormalities of a chronic kidney disease patient who presented with drowsiness and confusion by triphasic waves as typically seen in uremic encephalopathy ${ }^{\left({ }^{35}\right)}$. The typical features of an EEG in uremic encephalopathy are often non-specific such as a slowing of the alpha rhythm with excess delta and theta waves ${ }^{(10)}$.

Abnormal MRI findings were reported in $16 \%$ of studied subjects $(n=8)$ including mild brain atrophy in $37.5 \%(n=3)$ and encephalomalacia in $62.5 \%(n=5)$ this may be due to hypertensive encephalopathy, uremia, electrolytes disturbance, seizure or hypoxia. Ishikura et al. reported radiological abnormalities in 20 patients; these abnormalities extend to the grey matter (85\%) particularly in the frontal, temporal lobes 
and cerebellum ${ }^{(36)}$. Brain atrophy were estimated in $3(23 \%)$ of 13 children presented with chronic renal failure ${ }^{(37)}$. Conclusion

Neurological status in patients with end stage renal disease on maintenance hemodialysis therapy was impaired. Uremic neuropathy is highly prevalent in these patients. They developed polyneuropathy mostly of axonal polyneuropathy pattern. EEG is a useful tool for detection of subclinical or latent uremic encephalopathy and/or epileptogenic activity. Early detection and management of these neurological conditions may estimate a window to reduce physical disability in children with CKD.

\section{Abbreviations}

CKD: chronic kidney disease, UN: uremic neuropathy, GFR: glomerular filtration rate, EMG: Electromyography, EEG: Electroencephalography, MRI: Magnetic resonance imaging

\section{Declarations}

Ethical Approval: Research Involving Human Participants. The study was conducted in accordance with the Declaration of Helsinki. All participants provided written informed consent, and the Ethics Committee of Faculty of Medicine, Menoufia University approved the study protocol.

Consent for publication: not applicable as not required.

\section{Availability of data and material}

All data generated and analysed during this study are included within this article.

Competing Interests: the authors declare that they have no competing interests.

Funding: The authors have not declared a specific grant for this research from any funding agency in the public, commercial or not-for-profit sectors

Author contributions: All persons who meet the authorship criteria are listed as authors, and all authors certify that they participated sufficiently in the work to take public responsibility for the content, including participation in the concept, design, analysis, writing, or revision of the manuscript. Sameh Abd El Naby: analyzed the data, drafted and revised the paper, Ali El-Shafie: is the team leader and main coordinator of the study, Wael Bahbah: analyzed the data, drafted and revised the paper, Asmaa Mahmoud analyzed the data, drafted revised the paper and responsible for publishing.

\section{Acknowledgements}

All authors thank the participants for participation in the study and the team who helped in data collection. 


\section{References}

1. KDOQI (Kidney Disease Outcome Quality Initiative): Clinical Practice Guideline for Nutrition in Children with CKD: 2008 update. Executive summary. Am J Kidney Dis 2009; 53(2):11-104.

2. National Kidney F. K/DOQI: Clinical practice guidelines for chronic kidney disease: evaluation, classification, and stratification. Am J Kidney Dis 2002; 39: S1-266.

3. Brouns R and De Deyn PP. Neurological complications in renal failure: a review. Clin Neurol Neurosurg 2004; 107: 1-16.

4. Palmer SC, Navaneethan SD, Craig JC, et al. Systematic review: erythropoiesis-stimulating agents in patients with chronic kidney disease. Ann Intern Med 2010; 153:23-33

5. Patel N, Dalal P and Panesar M. Dialysis disequilibrium syndrome: a narrative review. Semin Dial 2008; 21:493-498.

6. Krishnan AV and Kiernan MC. Neurological complications of chronic kidney disease. Nat Rev Neurol 2009; 5: 542-551.

7. Krishnan AV, Pussell BA and Kiernan MC. Neuromuscular disease in the dialysis patient: an update for the nephrologist. Semin Dial 2009; 22: 267-278.

8. Arnold R, Kwai N, Pussell BA, et al. Effects of neuropathy on physical function and quality of life in moderate severity chronic kidney disease. Clin Neurophysiol 2014; 125: e4.

9. Kaltsatou A, Sakkas GK, Poulianiti KP, et al. Uremic myopathy: is oxidative stress implicated in muscle dysfunction in uremia? Front Physiol 2015; 6: 102.

10. Arnold R and Krishnan A. Neuropathy and other neurological problems in chronic kidney disease. In: Arici M (ed.) Management of chronic kidney disease. Berlin: Springer, 2014, pp.343-352.

11. Fahal IH and Bell GM. Uraemic myopathy: fact or fiction Int J Artif Organs 1998; 21: 185-187.

12. Bugnicourt JM, Godefroy $\mathbf{O}$, Chillon JM, et al. Cognitive disorders and dementia in CKD: the neglected kidneybrain axis. J Am Soc Nephrol 2013; 24: 353-363.

13. Arnold J, Sims D and Ferro CJ. Modulation of stroke risk in chronic kidney disease. Clin Kidney J 2016; 9: 29-38.

14. Latronico N, Bolton CF. Critical illness polyneuropathy and myopathy: a major cause of muscle weakness and paralysis. Lancet Neurol 2011; 10: 931-941.

15. Stevens RD, Marshall SA, Cornblath DR, et al. A framework for diagnosing and classifying intensive care unit-acquired weakness. Crit Care Med 2009; 37(Suppl): S299-S308.

16. Stern JM and Engel J: An Atlas of EEG Patterns. Philadelphia: Lippincott Williiam \& Wilkin 2004; 4:178-88.

17. Ghazan-Shahi S, Koh TJ, Chan CT. Impact of nocturnal hemodialysis on peripheral uremic neuropathy. BMC Nephrol. 2015;16:134.

18. Said G. Uremic neuropathy. Handb Clin Neurol. 2013;115:607-12. 
19. Ackil AA, Shahani BT, Young RR. Sural nerve conduction studies and late responses in children undergoing hemodialysis. Arch Phys Med Rehabil 1981;62: 487-491.

20. de Beaufort CE, Andre JL, Heimans JJ, van der Eerden HAM, van Diemen NGJ, Duc M-L, et al. Peripheral nerve function in children with end-stage renal failure. Pediatr Nephrol 1989;3:175-178.

21. Fuglsang-Frederiksen A, Pugdahl K. Current status on electrodiagnostic standards and guidelines in neuromuscular disorders. Clin Neurophysiol 2011;122: 440-445.

22. Afsharkhas L, Hoseininajad N, Kalbassi Z. et al. Neurologic manifestations in children and adolescents with chronic kidney diseases. IJCA 2015; 1(2):16-19.

23. Scorza FA, Albuquerque MD, Arida RM, Cysneiros RM, Henriques TMG, Scroza CA, et al. Seizure occurance in patients with chronic renal insufficiency in regular hemodialysis program.Arq Neuropsiquiatr 2005; 63(3-B): 757-760.

24. Chao CC, Wu VC, Tan CH, Wang YM, Tseng MT, Wu PC, et al. Skin denervation and its clinical significance in late-stage chronic kidney disease. Arch Neurol 2011;68: 200-206.

25. Preston DC, Shapiro BE. Electromyography and neuromuscular disorders clinical electrophysiological correlations, 2nd ed. Philadelphia PA: Butterworth Heinemann Elsevier; 2005. P 47-53.

26. Yoganathan S, Bagga A, Gulati S, et al. Prevalence and predictors of peripheral neuropathy in nondiabetic children with chronic kidney disease. Wiley On Line Library, Muscle and Nerve 2017; 57(5):792-798.

27. Elzouki A, Carroll J, Butinar D, Moosa A. Improved neurological outcome in children with chronic renal disease from infancy. Pediatr Nephrol 1994;8:205-210.

28. Van den Neucker K, Vanderstraeten G, Vanholder R. Peripheral motor and sensory nerve conduction studies in haemodialysis patients. A study of 54 patients. Electromyogr Clin Neurophysiol 1998; 38:467-474.

29. .de Camargo CR, Schoueri HM, da Veiga RL et al. Uremic neuropathy: an overview of the current literature. REV ASSOC MED BRAS 2019; 65(2):281-286.

30. Berretta JS, Holbrook CT 3rd, Haller JS. Chronic renal failure presenting as proximal muscle weakness in a child. J Child Neurol. 1986 Jan;1(1):50-2.

31. Gadewar Pradyumna, Sourya Acharya, Praveen Khairkar, Samarth Shukla, S.N. Mahajan. Dynamics of Electroencephalogram (EEG) in Different Stages of Chronic Kidney Disease. Journal of Clinical and Diagnostic Research. 2015; 9(3): 25-27.

32. Demir A.B., I.Bora, E.Kaigili, G.Ocakoglu. Assessment of Basic Features of Electroencephalography in Metabolic Encephalopathies. J. of Neurology Research 2014;4: 101-109.

33. Koçer Abdulkadir, HazmaYazgan, Nurhan Ýnce. Evaluation of the electrical activity of the brain in children and adult uremic patients. ErciyesMedical Journal. 2005; 27(3): 115-121.

34. Burn DJ, Bates D: Neurology and the kidney. J Neurol Neurosurg Psychiatry 1998; 65:810-821.

35. Arnold R, Issar T, Krishnan A et al."Neurological complications in chronic kidney disease" Journal of the Royal Society of Medicine Cardiovascular Disease 2016;5: 1-13. 
36. Ishikura K, Ikeda M, Hamasaki Y, Hataya H, Shishido S, Asanuma H, Nishimura G, Hiramoto R, Hond M. Posterior reversible encephalopathy syndrome in children: Its high prevalence and more extensive imaging findings. Am J Kidney Dis 200; 48: 231-238.

37. ElzoukiA, Carroll J, Butinar D, Moosa A. Improved neurological outcome in children with chronic renal disease from infancy. Pediatr Nephrol 1994;8:205-210.

\section{Tables}

Table (1): Distribution of demographic, clinical, and neurological examination in patients with CKD. 


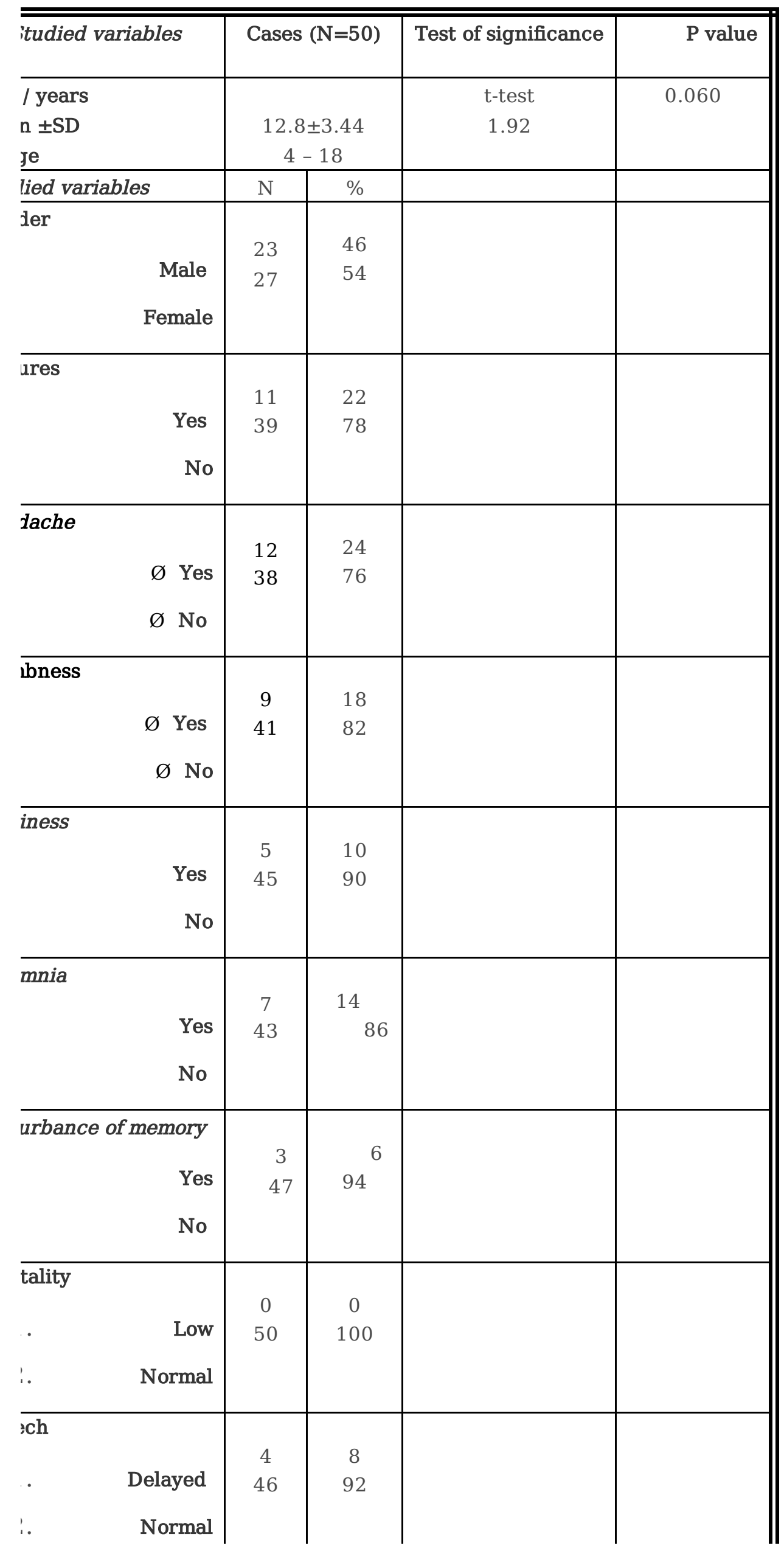




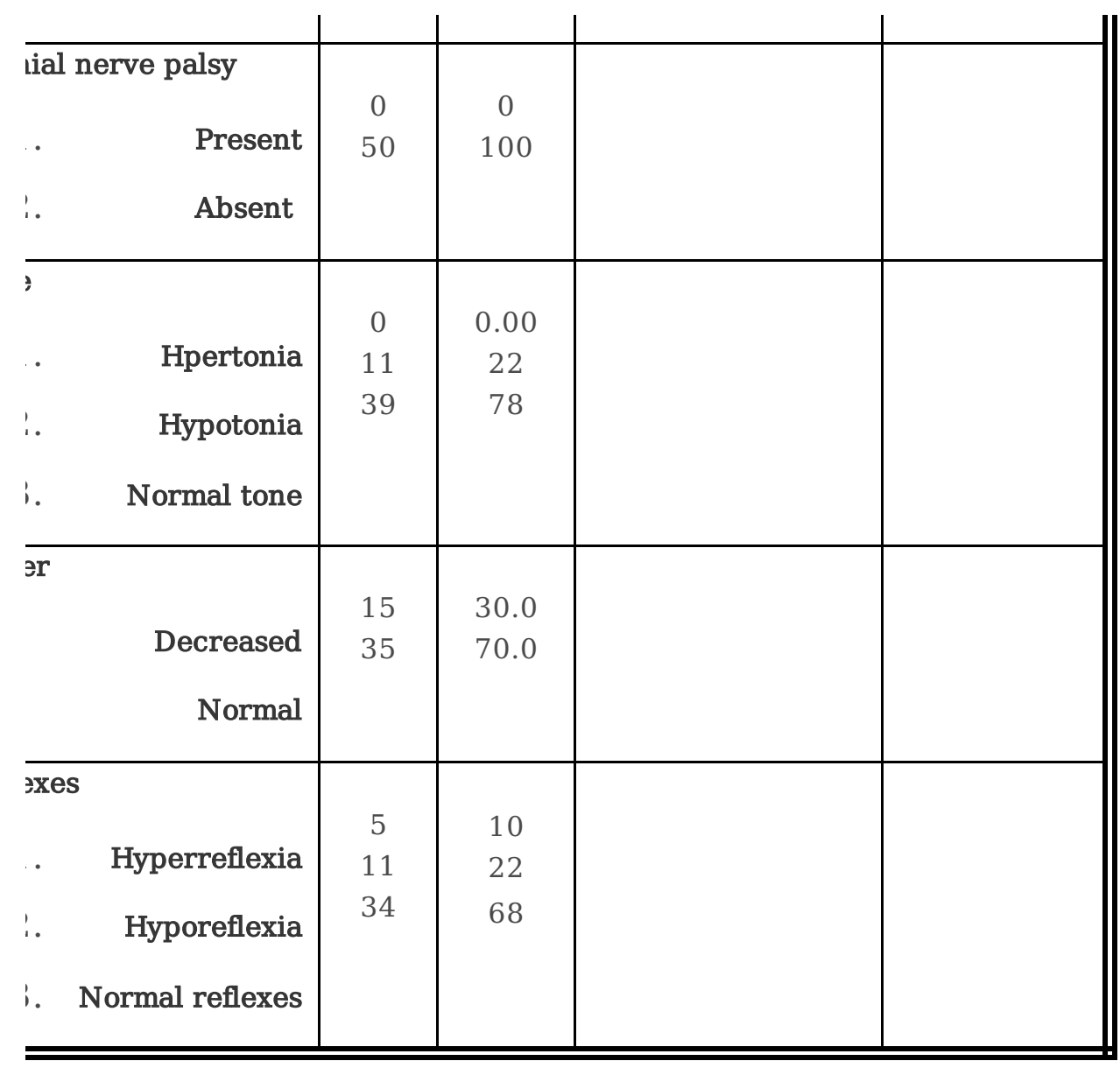

Table (2): Distribution of abnormal electrophysiological findings among studied patients:

\begin{tabular}{lr|c|c||}
\hline \hline rmal electrophysiological findings & No. & $\%$ \\
\hline tive & 39 & 78 \\
ve & 11 & 22 \\
\hline ve & N=11 & \\
& & \\
& Axonal & 2 & 81.8 \\
& & 18.2 \\
& Demyelinating & 0 & 0.00 \\
& Myopathy & \\
\hline \hline
\end{tabular}

Table (3): Nerve conduction findings among patients and controls 


\begin{tabular}{l|c|c|c|c||}
\hline \hline re conduction & $\begin{array}{c}\text { Cases } \\
\mathbf{N}=50\end{array}$ & $\begin{array}{c}\text { Controls } \\
\mathbf{N}=50\end{array}$ & t test & P value \\
\cline { 2 - 4 } & Mean \pm SD & Mean \pm SD & \\
\hline bial nerve & $44.06 \pm 6.64$ & $47.6 \pm 4.68$ & 3.12 & $\mathbf{0 . 0 0 2 *}$ \\
\hline n/s) & $5.10 \pm 1.07$ & $3.90 \pm 0.81$ & 6.29 & $\mathbf{0 . 0 0 0 1 *}$ \\
\hline ncy(ms) & $12.00 \pm 3.64$ & $15.42 \pm 1.51$ & 6.14 & $\mathbf{0 . 0 0 0 1 *}$ \\
\hline litude(mv) & $39.72 \pm 4.36$ & $52.76 \pm 4.51$ & 14.71 & $\mathbf{0 . 0 0 0 1 *}$ \\
\hline bial nerve & $5.46 \pm 0.86$ & $3.94 \pm 0.84$ & 8.91 & $\mathbf{0 . 0 0 0 1 *}$ \\
\hline n/s) & $1132 \pm 3.42$ & $17.04 \pm 1.97$ & 10.24 & $\mathbf{0 . 0 0 0 1 *}$ \\
\hline ncy(ms) & $40.80 \pm 4.40$ & $53.24 \pm 4.63$ & 13.77 & $\mathbf{0 . 0 0 0 1 *}$ \\
\hline litude(mv) & $5.28 \pm 0.97$ & $4.34 \pm 0.98$ & 4.82 & $\mathbf{0 . 0 0 0 1 *}$ \\
\hline eroneal nerve & \multicolumn{5}{|l|}{ n/s) } & $3.64 \pm 1.30$ & $4.84 \pm 0.86$ & $4.65 *$ & $\mathbf{0 . 0 0 0 1 *}$ \\
\hline ncy (ms) & $40.04 \pm 4.72$ & $53.30 \pm 4.52$ & 14.34 & $\mathbf{0 . 0 0 0 1 *}$ \\
\hline litude(mv) & $5.42 \pm 1.00$ & $4.00 \pm 0.81$ & 7.80 & $\mathbf{0 . 0 0 0 1 *}$ \\
\hline 3roneal nerve & $3.77 \pm 1.22$ & $4.94 \pm 0.82$ & 5.61 & $\mathbf{0 . 0 0 0 1 *}$ \\
\hline n/s) &
\end{tabular}

\# Mann-Whitney test; CV: Conduction velocity; Rt: right; Lt: left * *significant difference

Table (4): Description of Electromyography findings among patients and controls: 


\begin{tabular}{|c|c|c|}
\hline \multirow{2}{*}{$\begin{array}{l}\text { Electromyography } \\
\text { Findings }\end{array}$} & \multicolumn{2}{|c|}{ Cases $(\mathrm{N}=50)$} \\
\hline & No. & $\%$ \\
\hline \multicolumn{3}{|c|}{ Tibialis anterior muscle } \\
\hline $\begin{array}{l}\text { Motor unit } \\
\qquad \varnothing \text { Normal } \\
\varnothing \text { Large polyphasic } \\
\varnothing \text { Small polyphasic }\end{array}$ & $\begin{array}{l}41 \\
9 \\
0\end{array}$ & $\begin{array}{c}82 \\
18 \\
0.00\end{array}$ \\
\hline $\begin{array}{r}\text { Interference } \\
\qquad \begin{array}{r}\text { Normal } \\
\varnothing \text { Decreased }\end{array} \\
\varnothing \text { Early recruitment }\end{array}$ & $\begin{array}{l}39 \\
11 \\
0\end{array}$ & $\begin{array}{c}78 \\
22 \\
0.00\end{array}$ \\
\hline $\begin{array}{r}\text { Denervation } \\
\qquad \begin{array}{r}\varnothing \text { No } \\
\varnothing \text { yes }\end{array}\end{array}$ & $\begin{array}{c}41 \\
9\end{array}$ & $\begin{array}{l}82 \\
18\end{array}$ \\
\hline Gastrocnemius muscle & medial & ead \\
\hline $\begin{array}{l}\text { Motor unit } \\
\qquad \text { Normal } \\
\varnothing \text { Large polyphasic } \\
\varnothing \text { Small polyphasic }\end{array}$ & $\begin{array}{c}41 \\
9 \\
0\end{array}$ & $\begin{array}{c}82 \\
18 \\
0.00\end{array}$ \\
\hline $\begin{array}{r}\text { Interference } \\
\varnothing \text { Normal } \\
\varnothing \text { Decreased } \\
\varnothing \text { Early recruitment }\end{array}$ & $\begin{array}{c}39 \\
11 \\
0\end{array}$ & $\begin{array}{c}78 \\
22 \\
0.00\end{array}$ \\
\hline $\begin{array}{l}\varnothing \text { No } \\
\varnothing \text { Yes }\end{array}$ & $\begin{array}{c}41 \\
9\end{array}$ & $\begin{array}{l}82 \\
18\end{array}$ \\
\hline Gluteus Maximus mus & & \\
\hline $\begin{array}{l}\text { Motor unit } \\
\qquad \varnothing \text { Normal } \\
\varnothing \text { Small polyphasic }\end{array}$ & $\begin{array}{c}50 \\
0\end{array}$ & $\begin{array}{l}100 \\
0.00\end{array}$ \\
\hline $\begin{array}{r}\text { Interference } \\
\varnothing \text { Normal } \\
\varnothing \text { Decreased }\end{array}$ & $\begin{array}{c}50 \\
0 \\
0\end{array}$ & $\begin{array}{l}100 \\
0.00 \\
0.00\end{array}$ \\
\hline
\end{tabular}




\begin{tabular}{||lr|c|c||}
$\varnothing$ E Early recruitment & & \\
\hline Denervation & & 50 & 100 \\
1. & $\varnothing$ No & 0 & 0.00 \\
2. & $\varnothing$ Yes & & \\
\hline \hline
\end{tabular}

Table (5) Description of EEG findings among studied patients

\begin{tabular}{|c|c|c|}
\hline \multirow[t]{2}{*}{ EEG Findings } & \multicolumn{2}{|c|}{$\begin{array}{l}\text { Cases } \\
(\mathrm{N}=50)\end{array}$} \\
\hline & No. & $\%$ \\
\hline & 41 & 82 \\
\hline Normal EEG & 9 & 18 \\
\hline Abnormal EEG & & \\
\hline Abnormal EEG & $\mathrm{N}=9$ & \\
\hline - Generalized epileptogenic activity & 4 & 44.4 \\
\hline - Focal epileptogenic activity & 5 & 556 \\
\hline Focal epileptogenic activity: & $\mathrm{N}=5$ & \\
\hline Temporal & 2 & 40 \\
\hline - Frontal & 1 & 20 \\
\hline - Occipital & 2 & 40 \\
\hline
\end{tabular}

Table (6): Distribution of studied patients with MRI findings

\begin{tabular}{l|c|c||}
\hline \hline \multirow{2}{*}{ Studied variables } & \multicolumn{2}{|c|}{ Cases } \\
& \multicolumn{2}{|c||}{ (N=5) } \\
\cline { 2 - 3 } & No. & \% \\
\hline Normal MRI & 42 & 84 \\
tbnormal MRI & 8 & 16 \\
\hline tbnormal MRI & \multicolumn{2}{|c|}{$\mathbf{( N = 8 )}$} \\
\cline { 2 - 3 } Mild brain atrophy & 3 & 37.5 \\
& 5 & 62.5 \\
Encephalomalacia & & \\
\hline \hline
\end{tabular}

